\title{
WPS3582
}

\section{Does Temporary Migration Have to Be Permanent?*}

\author{
March 2005
}

\author{
Mohammad Amin and Aaditya Mattoo
}

\begin{abstract}
The choice between temporary and permanent migration is today central to the design of migration policies. We draw a distinction between the two types of migration on the basis of the associated social cost and the dynamics of learning by migrants. We find that unilateral migration policies are globally inefficient because they lead to too much permanent migration and too little temporary and overall migration. Existing international agreements on labor mobility, such as the WTO's General Agreement on Trade in Services, have failed to do better because they seek primarily to induce host countries to make commitments to allow entry. Instead, Pareto gains and more liberal migration could be achieved through multilateral agreements that enable host countries to commit to repatriation.
\end{abstract}

JEL: J24, F22.

Address: 1818 H Street, NW, Washington DC, 20433.

mamin@worldbank.org

amattoo@worldbank.org

The Policy Research Working Paper Series disseminates the findings of work in progress to encourage the exchange of ideas about development issues. An objective of the series is to get the findings out quickly, even if the presentations are less than fully polished. The papers carry the names of the authors and should be cited accordingly. The findings, interpretations, and conclusions expressed in this paper are entirely those of the authors. They do not necessarily represent the view of the World Bank, its Executive Directors, or the countries they represent. Policy Research Working Papers are available online at http://econ.worldbank.org.

${ }^{*}$ The views expressed in the paper are those of the authors and should not be attributed to the World Bank. This paper - a product of Trade, Development Research Group - is part of a larger effort in the group to assess the implications of liberalizing trade in services. We are grateful to an anonymous referee for useful comments. The research is supported in part by the U.K. Department for International Development. 


\section{Does Temporary Migration Have to Be Permanent?}

"There is nothing more permanent than temporary migration."

- Anonymous

"But I will harden his heart, that he shall not let the people go."

- $\quad$ Exodus 4:21

\section{Introduction}

How can the substantial gains from the international movement of labor be realized without creating the problems associated with permanent migration? To this difficult policy question, temporary migration schemes have often seemed an answer. But such schemes have proved extremely difficult to implement. Time and again, the naivety of their basic premise has been revealed by the permanent presence in host countries of supposedly temporary foreign workers. Many schemes have been abandoned, while some continue as much narrower avenues for de facto permanent migration. This paper addresses two questions. Why does temporary migration not stay temporary? And is there a solution to this problem? Both questions have received considerable casual but little analytical attention. 
We begin by making a stylized distinction between temporary and permanent migration, highlighting the sources of divergence between social and private welfare. From the host country's point of view, permanent migration is likely to have a higher socio-cultural-political cost (henceforth, social cost) than temporary migration; but temporary migration entails other "turnover" costs, particularly for employing firms, because it deprives them of the benefits of any investment in training. From the source countries' perspective, temporary migration is preferable to permanent since the former alleviates brain-drain and ensures a greater repatriation of skills (as well as remittances); but given a choice, emigrants are not inclined to return to their home countries because that implies a lower permanent income. Benefits from training and losses through brain drain are more relevant to the migration of the skilled and semi-skilled, on which this paper focuses.

To fix ideas, consider a two-stage game. Migration can occur in one or both stages, depending on the migration policies of the two countries. Firms in the host country can choose to train immigrants in the first stage. The cost of training is incurred in the first stage and is sunk thereafter, but the benefit from it accrues in the second stage. Depending upon the nature of social preferences, training technology and the skill level of migrants, several cases are possible. We focus on three.

The case which is the focus of this paper arises when (a) the host faces intermediate levels of social cost (from permanent migration) relative to the net benefit from training, and (b) the source prefers temporary to permanent migration, and either form of migration to no migration. The resulting non-cooperative Nash equilibrium outcome is permanent migration, but this is not the first-best outcome for either the host or the source. We believe 
that this outcome reflects a range of situations involving semi-skilled to skilled workers where host and source countries ideally want temporary migration only but are unable to implement it due to a commitment problem. When firms train immigrants in the first stage, they take into account the impact on their own future profits but not the social cost from permanent immigration. However, once the immigrants are trained, the training-cost is sunk in nature so that the host country finds it desirable to retain them permanently. The time consistent policy features too much permanent migration and too little temporary migration in each stage - as has happened with various guest worker schemes put in place by the United States and European countries. Both countries are worse off from this relative to the ex ante optimal policy. We show how a self-enforcing cooperative agreement between the two countries can reduce the commitment problem leading to global Pareto gains.

The second case arises when condition (b) above is maintained but (a) is relaxed: the host country faces a social cost that is small relative to the net benefit from training. The result is permanent migration only; now, however, this is first-best for the host but not for the source. We believe that this outcome reflects part of current skilled migration from developing to industrial countries. For example, countries like Australia and Canada select permanent migrants through a points system which attaches a high weight to advanced education. It is also likely that some ostensibly temporary migration schemes, like the US specialty occupation visas, are intended to be de facto permanent migration schemes and the temporary phase functions merely as a screening device. In such situations since the source countries prefer temporary to permanent migration there is a direct conflict of interest between source and host. International cooperation cannot lead to a Pareto superior 
outcome, but could succeed in redistributing global welfare in a more egalitarian way.

The final case arises when condition (a) is the same as in the first case, but (b) is relaxed: the costs of brain drain are so high that the source prefers no migration to permanent migration. The outcome is that the source country limits emigration. While this case is probably of limited empirical significance today, we do see signs of its relevance in the attempts by various source countries, from the Caribbean to Africa, to somehow restrict the outflow of skilled workers. We show that the level of temporary emigration can be increased and brain-drain reduced through a self-enforcing cooperative agreement prompting the source country to relax the emigration constraint. As a consequence, both countries are better off.

Why do we not observe more international cooperation on labor mobility despite the potential global benefits suggested above? One reason is that we are not operating in a two-country world, but in a world where host countries have access to multiple small sources who cannot easily coordinate policy. Since current migration levels are relatively small, a host country can simply substitute one source country by another. We show that bilateral agreements are, therefore, not likely to have a big effect due to their weak enforcement power -punishment by a single source inflicts little pain on the host. To remedy their individual weakness, source countries must take a coordinated approach by negotiating jointly with the host countries.

Our results have implications for the design of international cooperation on migration policies. On the insistence of developing countries, the WTO's General Agreement on Trade in Services (GATS) and some regional trade agreements have included the "temporary presence of natural persons" as a mode of trading services. Trade negotiations have, however, 
delivered little additional scope for labor mobility. Countries have been unwilling to commit to access beyond levels that were already allowed. In contrast, bilateral agreements focusing on labor alone (e.g. between Spain and Ecuador, Canada and the Caribbean, Germany and Eastern Europe) have led to somewhat greater access for foreign labor, and this movement has been genuinely temporary.

We believe that the differing experiences with trade and pure labor agreements is revealing. The former have failed to deliver scope for greater labor mobility because they have dealt with neither the time inconsistency of migration policy nor the conflict of interests between host and source countries. The focus of these agreements has been on inducing host countries to commit to greater access when a major problem has been the hosts inability to commit to returning migrants. Bilateral labor agreements in contrast impose at least an implicit obligation on the host to repatriate labor. These agreements have thus addressed to some extent the host's commitment problem, and succeeded in delivering slightly greater openness. Their limited impact, however, is attributable to the small size of the source countries relative to the host and the lack of coordination between source countries.

Existing analytical work on migration policy has focused on the welfare consequences for host and source countries of allowing free or freer migration (see, for example, Bhagwati, 1991; Borjas, 1995). The issue of temporariness has been addressed primarily from the individual migrant's point of view, with the objective of characterizing the determinants of optimum duration of stay abroad (Hill 1987; Stark et. al. 1997; Dustmann and Kirchkamp 2002). There is also work on the social costs, learning experience and brain drain associated with migration (Commander et. al. 2003; Schiff 2000). The present paper builds on this previous 
work to draw a distinction between temporary and permanent migration policy, and shows how self-enforcing international agreements can improve upon unilaterally optimal policies of the participating countries.

The structure of the rest of the paper is as follows. In section 1 we describe the basic setup of the model. In section 2 we derive equilibrium policies when these are set unilaterally. In section 3 we demonstrate gains from cooperation. A summary of the results and scope for future work are provided in the conclusion. Some extensions of the model are discussed in the Appendix.

\section{Section 1: The model}

We begin with a model in which there are two countries called host $(H)$ and source $(S)$. There are two stages, labelled 1 (current stage) and 2 (future stage). These will be indexed by subscript $t=1,2$. The wage in the host country is exogenously given and fixed at $w$, and assumed to be significantly higher than the wage in the source country at all levels of migration considered here. ${ }^{1} \quad$ In the absence of any restrictions, any worker in $S$ would prefer to migrate to $H$, and to migrate permanently rather than temporarily.

We suppose that $H$ produces two goods, $X, Y$ under perfect competition and constant returns to scale. We will treat $Y$ as the numeraire good which can be costlessly traded across countries. Assume that all natives of $H$, equal to $L_{y}$, are employed in sector $Y$ with each of them producing $b>0$ units of the good. Good $X$ is assumed to be a non-traded

\footnotetext{
${ }^{1}$ This is a standard assumption in the literature and typically attributed to differences between the two countries in technology or complementary inputs.
} 
good, produced by using domestically supplied capital, $K$, and skilled labor which is supplied entirely by $S .^{2}$ Without loss of generality we set $K=1$.

The two-stage game

The structure of the game in the absence of cooperation between the two countries is as follows. At the beginning of stage 1 the government of the host country (henceforth, government) invites $M_{1}$ number of immigrants and assigns them across firms in sector $X$. The value of $M_{1}$ is endogenously determined in the model. We assume that there are a large number of symmetric firms behaving as price and wage takers. Capital is freely mobile across firms at all times and there is a perfectly competitive capital market.

Next each firm decides how much output to produce in stage 1 and how much capital and labor to hire subject to the quota of immigrants assigned to it. It also simultaneously decides how many immigrants to train, which involves imparting firm-specific knowledge to them. Available evidence broadly supports the importance of training by firms of employees, including immigrants. For example, a survey of 1,145 senior level managers and labor leaders in Canada revealed that "upgrading the skills of current employees" was the most important action they would take in addressing skill requirements of their respective organizations in the near future (CLBC, 2002, page 1). Data from the 1998-99 Workplace and Employee Survey for Canada also shows that employer participation in training new immigrants is significant: about $48 \%$ of all recent immigrants obtained employer sponsored training. The incidence of training is much higher for permanent relative to temporary immigrant workers (49.2 versus

\footnotetext{
${ }^{2}$ It is not important to our results that sector $X$ employs immigrants alone and $Y$ employs natives alone. However, the assumption helps to simplify the algebra and draw sharp results.
} 
31.7 percent). The incidence is also significantly greater for more highly educated workers, and for professionals relative to technical and clerical staff.

Table 1: Employer sponsored training in 1998-99

\begin{tabular}{|l|c|c|}
\hline Immigrant category & \% of recent immigrants in the & \% of Canadian-born in the \\
category receiving training & category receiving training \\
\hline All & 47.7 & 56.3 \\
\hline With no post-secondary education & 34.5 & 50.6 \\
\hline With post-secondary education & 55.4 & 61.9 \\
\hline Non-permanent workers & 31.7 & 43.2 \\
\hline Permanent workers & 49.2 & 57.7 \\
\hline Professionals & 63.8 & 69.4 \\
\hline Technical/trades & 44.6 & 53.2 \\
\hline Clerical/administrative & 50.3 & 55.7 \\
\hline
\end{tabular}

Source: Workplace and Employee Survey, 1998-99. Sample size: 23,540.

For simplicity, the costs and benefits from training are assumed to have the following structure. Let $c>0$ denote the exogenously given and constant cost of training each immigrant, which is incurred in stage 1. Training involves imparting firm-specific knowledge to a worker while currently employed (on the job training). Without loss of generality we assume that the efficiency unit of each immigrant in stage 1 equals unity. Let $\gamma>1$ denote the efficiency unit of a trained worker in stage 2 to his stage 1 employer. ${ }^{3}$ Let $M_{T}$ denote the

\footnotetext{
${ }^{3}$ There is little formal work on employer sponsored training of immigrants. However, there is some evidence on training in general which is broadly consistent with the structure of the model. For example, Cohen and Eckstein (2002) find that training of immigrants in Israel had a significant effect on their productivity
} 
immigrants who undergo training. $\quad M_{u} \equiv M_{1}-M_{T}$ is the number of untrained immigrants available at the end of the first stage.

Now the second stage begins. In this stage the government decides how many new immigrants to invite from $S$ and how many trained and untrained immigrants to retain from stage 1 . Let these levels be denoted by $m_{2}, M_{T}^{*}$ and $M_{u}^{*}$, respectively. At the same time the government decides how to allocate them across firms. We assume that the efficiency unit of each new immigrant equals unity. Firms decide how much to produce, how much capital and labor to hire subject to the the number of immigrants assigned to it. Production occurs and consumption is realized for the second stage, and the game ends.

Before solving the equilibria of the game we need to outline the production technology, the utility function and the social cost. These are as follows.

\section{Production and welfare in the host country}

Let $N_{t}$ denote the total efficiency units of migrants in stage $t$. We have that $N_{1}=M_{1}$ and $N_{2}=m_{2}+M_{u}^{*}+\gamma M_{T}^{*}$. Throughout we will maintain that $M_{T}^{*} \leq M_{T}$ and $M_{u}^{*} \leq M_{u}$. Aggregate production of $X$ is given by: $X_{t}=X\left(K, N_{t}\right)=K^{0.5} N_{t}^{0.5} \cdot{ }^{4}$

Let $W_{t}$ denote the welfare of all the natives of $H$. This depends on the utility from the consumption of the two goods net of the social cost of immigration. We assume that the former is given by a quasi-linear function, which after normalizing the total natives of $H$ to

and wage rate. However, the gains in the immediate future after training were very modest and there was a lag before the gains were realized.

${ }^{4}$ Note that the aggregate production of $X$ is independent of the size-structure of firms. This is simple to see for stage 1 given that all firms are symmetric, production is subject to constant returns to scale and that capital is perfectly mobile across firms. For this property to hold in stage 2 as well we merely need to ensure that trained immigrants who are retained are not arbitrarily assigned across firms since their productivity is higher when assigned to their stage-1 employer. It will be clear from the solution below that a trained migrant if retained will always be assigned to his stage- 1 employer. With this allocation so determined, aggregate output can be expressed simply as a function of $K$ and $N_{2}$ as above. 
unity, can be expressed as: $\alpha X_{t}^{c}-X_{t}^{c 2}+Y_{t}^{c}$ where $X_{t}^{c}\left(Y_{t}^{c}\right)$ is the aggregate consumption of $X(Y)$ in stage $t$ and $\alpha>0$ is an exogenously given parameter of the model. We assume that immigrants while in $H$ consume (or remit) good $Y$ only. The motivation for this is that typically immigrants are concentrated in a few sectors while their consumption is spread out over a large variety of goods. Thus, they consume an insignificant proportion of the good they themselves produce. The motivation for the social cost and its structure is as follows. Social cost of immigration

In the context of this paper, social cost includes any negative effect on the natives of the host country from immigration which is not taken into account by the host firms or the migrants. There is a growing body of literature identifying the nature of these costs which can take a myriad of forms and vary across countries. For example, in some cases immigrants and natives differ significantly in language, customs, values and culture so that the former adversely affect the survival of local cultures and life-styles (Bliss, 1994, Schiff, 1992). ${ }^{5} \quad$ The existence of racial prejudice and xenophobia also implies that natives suffer from increased immigration. For example the International Social Survey Program (1995) reveals that the percentage of respondents who believe immigration is bad ranged from $43 \%$ in Canada to $85 \%$ in the United Kingdom and the Netherlands. Some costs may be more economic in nature. For example, it is often argued that immigrants make demands upon public services without contributing as much to the public exchequer as natives. ${ }^{6}$ Also, new immigrants may displace natives from certain sectors or regions which can lead

\footnotetext{
${ }^{5}$ See, for example, Putnam (1995), Carlton (1995), Coleman (1987, 1988, 1990), Knack and Keefer (1997) and Schiff (1992).

${ }^{6}$ This concern is less relevant for immigration of skilled workers which is the focus of this study. For more details on this point see, for example, Lee and Miller 2000, Auerbach and Oreopolis 2000, Storesletten 2000 and Borjas 1999.
} 
to higher unemployment amongst natives or adjustment costs borne either by the natives directly or by their government. For example, Winter-Ebmer and Zweimüller (1998) show that an increase in the immigrant share by $1 \%$ point increased unemployment duration of Austrian manufacturing workers by about $5 \%$. This increase was most pronounced for young workers. Hatton and Tani (2003) find a significant geographical displacement of natives from immigration in the UK. ${ }^{7}$

The important point in the context of this paper is not the mere existence of such negative externalities, but how these vary between temporary and permanent migrants. There is no formal work in this area but available evidence suggests that permanent migrants impose larger social costs than temporary ones. For example, in a study based on a sample of 781 Batswana (citizens of Botswana), Campbell (2003) reports that owing to considerable social aversion towards immigrants, short and specific-term residence are preferred over permanent residence by immigrants. Winters et. al. (2002) also suggest that the temporary movement of unskilled workers poses fewer cultural or integration threats and makes less demand upon public services than permanent migration. One reason is that temporary workers are less likely to be accompanied by their families, including children who utilize the school system, and less likely to impose old-age related net costs on the host society.

Based on this evidence, the social cost takes the following form in our model. Measured in terms of the total loss in utility of all the natives of $H$, the social cost of each permanent migrant in stage 2 is equal to $S_{p}>0$. Without much loss of generality we set the social cost

\footnotetext{
7 The impact of immigration on unemployment of natives is likely to be more significant in those cases where the labor market is less flexible as, for example, shown by Angrist and Kugler, 2002 in their study of EU countries. When labor markets are flexible, natives may experience some decline in the wage rate from immigration. The evidence on the size of this effect is mixed. See, for example, Borjas, 2003.
} 
of a temporary migrant to zero. ${ }^{8}$ Let $S C_{t}$ denote the total social cost in stage $t$. We have that $S C_{1}=0$ and $S C_{2}=\left(M_{T}^{*}+M_{u}^{*}\right) S_{p}$.

Aggregate welfare is given by: $W_{t}=C S_{t}+P S_{t}-S C_{t}$ where $C S_{t}\left(P S_{t}\right)$ is the aggregate consumer (producer) surplus from $X$ in stage $t$. There is no immigration tax or migration related quota-rent in our model. Computing we get: $W_{2}=u\left(X_{2}\right)-w\left(M_{T}^{*}+M_{u}^{*}+m_{2}\right)-$ $\left(M_{T}^{*}+M_{u}^{*}\right) S_{p}$ and $W_{1}=u\left(X_{1}\right)-w M_{1}-c M_{T}$. Lastly, assume that there is no discounting so that, ex ante, national welfare of $H$ equals $W_{1}+W_{2} \equiv \Omega$.

\section{Section 2: Solution to the two-stage game}

The decision on whether to train migrants will play a central role in our model. This decision depends on how the quota is allocated across firms in the two stages, and on how firms form expectations about future policy. We assume that the allocation of quota is symmetric across all firms in each stage and that if some firms do not wish to utilize their quota fully then the surplus is equally distributed across the remaining firms. ${ }^{9} \quad$ Regarding the structure of expectations, we impose three plausible restrictions: (i) each firm treats the training decision of the remaining firms as given and independent of its own action; (ii) each firm correctly anticipates that the outcome in stage 2 is given by the solution outlined below; (iii) each firm correctly anticipates that the allocation of migrants across firms in stage 2 is determined by the symmetric quota rule stated above. ${ }^{10}$

\footnotetext{
${ }^{8}$ It is assumed here that temporary and permanent migrants differ in their social cost in stage 2 but not in stage 1. Our results are unaffected if permanent migrants imposed a higher cost in stage 1 as well.

${ }^{9}$ By default, if some migrants are left in the end then they are returned to the source country.

${ }^{10}$ Relaxing the assumption of symmetric allocation of quotas and of non-naive expectations does not change our results qualitatively. For more details on this point see Appendix C.
} 
It is straightforward to see that irrespective of the parameter values, the government will never retain any untrained immigrant. The reason for this is that, viewed at the beginning of stage 2 , if an untrained immigrant is replaced by a new one then total output and wage bill will remain unchanged but the total social cost will decrease by $S_{p}$. This will increase $W_{2}$ by the same amount. Thus, we have that in any time consistent solution $M_{u}^{*}=0$. The solution to the remaining endogenous variables admits a large range of possibilities depending on the parameter values. For tractability we distinguish between two sets of parameter values depending on whether the following condition holds or not

$$
S_{p}<w(\gamma-1) \quad \ldots \ldots . \quad C 1
$$

Interpretation of $C 1$ is simple. Viewed at the beginning of stage 2, if a trained immigrant is replaced by $\gamma$ new immigrants then $W_{2}$ will rise by $S_{p}$ on account of lower social cost but it will fall by $w(\gamma-1)$ due to a higher wage bill. There is no other effect on $W_{2}$ since the proposed substitution leaves $X_{2}$ unchanged. In other words, since the wage rate is fixed at $w$, workers with higher productivity increase producer surplus and hence $W_{2}$ due to a lower effective wage. This effect is likely to arise in more general settings than ours provided that firms are able to capture some rent from firm-specific training. $C 1$ states that, ex post, the benefit from lower effective wage dominates the higher social cost of retaining trained immigrants.

In the rest of this section, we derive the solution from the host country's point of view and assume that the source country does not intervene in the migration process. ${ }^{11}$

\footnotetext{
${ }^{11}$ In section 3 we discuss the implications of an active source country for our results.
} 


\subsection{When $C 1$ does not hold}

In this case the ex post optimal policy of the host country is to return all stage 1 immigrants. Firms correctly anticipates this and hence no training occurs. Further, in this case $S_{p}>w(\eta-1)$ implying that the government will always prefer new immigrants to untrained ones. Consequently, the full time consistent solution features temporary migration only with $M_{1}=m_{2}=\alpha^{2} / 4(w+1)^{2} \equiv \hat{m}_{2}$ and $M_{T}=M_{T}^{*}=M_{u}^{*}=0$.

\subsection{When $C 1$ holds}

First consider the solution to the second stage of the game. Let $M_{T}^{* t c}\left(m_{2}^{t c}\right)$ denote the solution values of $M_{T}^{*}\left(m_{2}\right)$. We have

$$
\begin{aligned}
M_{T}^{* t c} & =\min \left\{M_{T}, \hat{M}_{T}^{*}\right\}, \hat{M}_{T}^{*}=\gamma \alpha^{2} / 4\left(w+S_{p}+\gamma\right)^{2} \\
m_{2}^{t c} & =\max \left\{0, \hat{m}_{2}-\gamma M_{T}^{* t c}\right\}, M_{u}^{*}=0
\end{aligned}
$$

Intuitively, when $C 1$ holds the government prefers, ex post, to retain trained immigrants over others and hence begins by hiring them first. The marginal benefit and cost is equalized when $\hat{M}_{T}^{*}$ number of them are hired. This constitutes an upper limit to the value of $M_{T}^{* t c}$ . Noting that $M_{T}^{*} \leq M_{T}$ we get $M_{T}^{* t c}$ value as shown above. From the expression for $W_{2}$ it is simple to see that trained and new immigrants are substitutes of each other and for each trained migrant retained, the government finds it optimal to lower new immigrants by $\gamma$. This explains the solution for $m_{2}^{t c}$.

Summarizing: Viewed ex post, permanent migrants impose a higher social cost but the host benefits on account of the training-rent extracted from them. The relative strength of these two factors determines their overall desirability compared to temporary migrants. 
Now consider the solution to the first stage of the game when $C 1$ holds. In this stage the government decides how many immigrants to invite and firms decide how many to train. For any individual firm, the training decision is based on the training cost, $c$, and the expected future benefit. Suppose that $c$ is not too large so that some training is privately profitable, for which a sufficient condition is: ${ }^{12}$

$$
c<S_{p} \quad \ldots \ldots . C 2
$$

Given $C 1$,condition $C 2$ ensures that the equilibrium value of $M_{T}$ is strictly positive. ${ }^{13}$

When $C 1$ and $C 2$ hold and the source country is inactive then the unique time consistent solution features firms behaving symmetrically and:

$$
\begin{aligned}
M_{T}^{* t c} & =\min \left\{M_{1}, \hat{M}_{T}^{*}\right\} \\
M_{1} & >0, M_{T}=M_{T}^{* t c}, M_{u}^{*}=0, m_{2}=m_{2}^{t c}
\end{aligned}
$$

The solution states that $M_{1}$ is strictly positive. This follows directly from the fact that the value of the marginal product of labor in $X$ approaches positive infinity as $M_{1}$ approaches zero and the marginal social cost of immigrants is finite (bounded above by $2 w+c+S_{p}$ ). The interpretation for $M_{u}^{*}, m_{2}$ values is as discussed above. The solution for $M_{T}^{* t c}$ implies that it is either constrained by the available pool of potential trainees $\left(=M_{1}\right)$ or it equals the maximum number of trained migrants that the government will retain in stage $2\left(=\hat{M}_{T}^{*}\right)$. The interpretation is simple. Suppose first that $M_{1}$ is non-binding so that $M_{T}^{* t c}=\hat{M}_{T}^{*}$.

\footnotetext{
${ }^{12}$ If $c$ is too large, then there will be no training in equilibrium. The solution then is exactly as in Section 2.1 .

${ }^{13} C 2$ is not a necessary condition for $M_{T}>0$. This holds under weaker conditions too. However, under weaker conditions the equilibrium may not be stable without further restrictions. $C 1-C 2$ ensure that the time consistent solution exists, is unique and globally stable.
} 
Since firms behave symmetrically, each firm trains $\hat{M}_{T}^{*} / n$ migrants. No firm can do better by training an extra migrant because under the quota rule and the structure of expectations, it realizes it will not get to retain any more workers in the future. We need to check if it can do better by reducing the level of training. The marginal cost to the firm of training and subsequently hiring an extra migrant is $c+w$ and the marginal benefit equals $P_{2} \partial X_{2} / \partial M_{T}$. It can be easily checked that at the proposed solution the latter equals $S_{p}+w$. Note that under $C 2$ the marginal benefit is higher than the marginal cost so that a small downward revision in the level of training is not optimal for the firm. It is simple to see that this holds for finite downward revisions also because $P_{2} \partial X_{2} / \partial M_{T}$ can only increase as $M_{T}$ falls below $\hat{M}_{T}^{*}$ while the marginal cost is constant. ${ }^{14}$ Now suppose that $M_{1} \leq \hat{M}_{T}^{*}$ so that our solution implies that $M_{T}^{* t c}=M_{1}$. The intuition for this result can be seen by following exactly the same steps as for the case with $M_{1}>\hat{M}_{T}^{*}$ and noting that $P_{2} \partial X_{2} / \partial M_{T}$ is non-increasing in $M_{T}$ with $m_{2}$ adjusted appropriately to equal $m_{2}^{t c}$.

Summarizing: We have derived the time consistent solution when the source country is inactive. When the social cost is high relative to the benefit from training, the equilibrium features temporary migration only. However, when the social cost is below a critical level relative to the training-benefit, there is some permanent migration in equilibrium.

\footnotetext{
${ }^{14}$ When a single firm reduces the number of migrants it trains then it will expect $M_{T}$ to fall since it treats the training levels of other firms as given. From the definition of $N_{2}$ and the structure of $m_{2}^{t c}$ it can be easily seen that this can never increase the value of $N_{2}$ which in turn implies that $P_{2} \partial X_{2} / \partial M_{T}$ cannot fall.
} 


\section{Section 3: International agreements}

In this section, we analyze the efficiency of the solution derived above and establish the scope for international agreements.

\subsection{The source country}

So far we have approached the issue of migration policy from the host country's point of view. Consider now the welfare of the source country and the instruments available to it. Given our assumptions, the migrant is better off in the host country, and would prefer permanent to temporary migration. ${ }^{15}$ The impact on the source country's welfare from emigration of skilled and semi-skilled workers is less clear and is at the heart of the "brain drain" literature. Table 2 provides some evidence on the size of brain drain. ${ }^{16}$ While the literature on brain drain focuses on the net benefits to the source country from the emigration of its skilled workers, our interest is in the relative benefits of permanent and temporary migration.

\footnotetext{
${ }^{15}$ In richer models migrants may prefer to move back to their original country after working for a few years abroad due to utility from consumption in their own country. This does not affect the qualitative nature of our results except in the extreme case where migrants prefer to return so soon that the problems associated with permanent (long term) migration do not arise at all.

${ }^{16}$ The loss of skilled workers due to brain drain is likely to be higher than suggested by the table when we account for the fact that skilled emigrants are not only the highly educated ones but also the most able and qualified amongst the educated ones.
} 
Table 2: Tertiary Educated Population in OECD Countries

Relative to Tertiary Educated Population at Home, $2000(\%)^{17}$

\begin{tabular}{|c|c|}
\hline Country/Region & Secondary education \\
\hline Jamaica & 504.68 \\
\hline Mozambique & 328.8 \\
\hline Mauritius & 308.76 \\
\hline Gambia & 223.66 \\
\hline Congo & 100.99 \\
\hline Ghana & 77.51 \\
\hline Kenya & 70.43 \\
\hline Sri Lanka & 55.92 \\
\hline Senegal & 41.16 \\
\hline El Salvador & 35.71 \\
\hline Tunisia & 26.73 \\
\hline Philippines & 18.61 \\
\hline Mexico & 14.91 \\
\hline India & 6.22 \\
\hline China & 3.73 \\
\hline
\end{tabular}

Source: Tertiary educated population in OECD from Dumontand Lemaitre (2004), Tertiary educated population in countries of birth from Barro and Lee (1993) and its update at www.ksg.harvard.edu/CID

\footnotetext{
17 The table was presented by Robert Lucas at a seminar on migration organized by the The World Bank, Washington DC.
} 
It seems reasonable to assume that for a wide variety of situations, the source country is better off with temporary migration (Commander et al. 2003). Temporary migration alleviates the costs of brain drain, and is likely to be associated with a higher repatriation of incomes than permanent migration. ${ }^{18}$ Further, anecdotal evidence suggests that returnmigrants bring back with them valuable skills acquired abroad which enhance productivity in the source country. For example, there is evidence that a group of skilled blue-collar workers from Moldova who worked in companies in Slovenia for six months acquired industrial and technical skills on par with their Slovene counterparts which they brought back to their home country (Ellerman, 2003). ${ }^{19}$

Our model can be easily extended to include such benefits to the source country. For instance, we can assume that in addition to the firm specific training immigrants acquire skills also through learning-by-doing which can be easily transferred across firms and countries. The qualitative nature of all our results will be virtually unchanged by this extension. The significance of these benefits and costs also determines the relative ranking at the margin of permanent and no migration. When such costs are small (large), permanent migration would (would not) be preferred to no migration.

We will first assume the following preference structure: the source country prefers temporary migration to permanent migration to no migration. Later we shall also explore the implications of alternative preference structures. We now proceed to analyze the scope for international agreements.

\footnotetext{
${ }^{18}$ We are abstracting from the larger benefits that may come from permanent migration due to the greater scope it offers for cumulative saving and learning.

${ }^{19}$ There is also substantial evidence in the literature on growth theory that learning-by-doing is important in human capital accumulation.
} 


\subsection{No gains from cooperation}

First consider the case when $C 1$ does not hold. In the previous section we showed that in this case the time consistent policy features "temporary migration only" and "no training". Now consider the ex ante optimal policy which the government will choose if it could credibly commit to future policy at the beginning of stage 1 . Since $C 1$ does not hold, it follows that $c+S_{p}>w(\gamma-1)$. Interpretation of this inequality is simple. Viewed ex ante, if a trained immigrants is replaced by $\gamma$ new ones in stage 2 then overall welfare $\left(W_{1}+W_{2}\right)$ will increase by $c+S_{p}$ due to lower training and social cost. However, welfare will decrease by $w(\gamma-1)$ due to a higher wage bill. The ex ante optimal policy will feature "temporary migration only" if and only if the previous inequality holds. Thus, in this case the ex ante optimal policy involves the government inviting $\hat{m}_{2}$ number of immigrants in each stage with no permanent migration and no training which is exactly the same as the time consistent solution. It is simple to see now that there are no Pareto gains from cooperation here. That is, any movement in $w$ or migration level will make at least one country worse off, and any move from temporary to permanent migration will make both the countries worse off. In terms of the real world, this situation applies to much of unskilled migration. At the low-skill end there is little scope for training and the net benefit from training, if any, is very small. The previous inequality is almost guaranteed to hold then.

Summarizing: Host countries with high social cost can implement their first best policy of "temporary migration only". This is the first best policy for source also. Thus, there are no Pareto gains from cooperation..$^{20}$

\footnotetext{
${ }^{20}$ We note here that when the both countries have active migration policies, multiple equilibria may arise.
} 


\subsection{Gains from cooperation}

Now consider the case when $C 1$ holds. To analyze the gains from cooperation we put forward the following condition

$$
c+S_{p}>w(\gamma-1) \quad \ldots \ldots . C 3
$$

As discussed above, $C 3$ implies that the ex ante optimal policy of the host country is temporary migration only at level $\hat{m}_{2}$ in each stage.

Suppose that $C 3$ holds along with $C 1, C 2$. As discussed in the introduction, this situation is most likely for host countries with intermediate levels of social cost and for skilled and semi-skilled immigrants. In this situation, both countries prefer a policy of temporary migration only (implied by $C 3$ ) but this is not time consistent (by $C 1, C 2$ ). Given its preference structure, the source country cannot beneficially intervene unilaterally. In addition to this globally sub-optimal structure of migration, another potential inefficiency relates to the equilibrium value of $M_{1}$. To see this, consider how the host country acting unilaterally chooses $M_{1}$. Starting from zero, as $M_{1}$ rises there are two competing effects on overall welfare. Since $M_{T}^{* t c}$ rises with $M_{1}$ this will lower overall welfare with $C 3$ in place. At the same time $X_{1}$ will rise along with the total wage bill. From the definition of $\hat{m}_{2}$ it follows that, neglecting the change in $M_{T}, W_{1}$ will increase with $M_{1}$ over the interval $\left(0, \hat{m}_{2}\right)$ and decrease thereafter. Thus, overall welfare is strictly decreasing in $M_{1}$ for $\forall M_{1} \geq \hat{m}_{2}$ but this relationship is ambiguous otherwise. It follows immediately from this that the solution value of $M_{1}$ will never be strictly greater than $\hat{m}_{2}$.

For example, a complete ban on migration by both the countries in each stage is a (weak) subgame perfect Nash equilibria of the game. Gains from cooperation may then arise in jointly moving from this autarky state to one involving some migration. These are "pure coordination" gains from cooperation and we rule them out from our analysis throughout the paper in order to focus on other motivation for cooperation. This makes it only more difficult for us to establish the need for international agreements. 
The key question then is if lowering $M_{1}$ below $\hat{m}_{2}$ is desirable for the host country. For this note that with $M_{T}$ held fixed momentarily, $W_{1}$ achieves its maxima at $M_{1}=\hat{m}_{2}$. Thus, a small reduction in $M_{1}$ from $\hat{m}_{2}$ has a second order effect on $W_{1}$. Further, if $M_{T}$ falls too then this will increase overall welfare through a first order effect. However the infinitesimal change may or may not reduce the value of $M_{T}$. For example, if $\hat{M}_{T}^{*}<\hat{m}_{2}$ then not all stage 1 immigrants will be trained so that lowering $M_{1}$ by a small amount will leave $M_{T}$ unchanged. Of course, large reductions in $M_{1}$ (to a level below $\hat{M}_{T}^{*}$ ) will lower $M_{T}$ but without further restrictions on parameter values it is impossible to see whether such a finite change will increase overall welfare of the host country (because $W_{1}$ decreases and $W_{2}$ increases). To resolve this problem we impose a simple condition typically observed in the real world that temporary and permanent migration coexist. That is, $m_{2}^{t c}>0$ and $M_{T}^{* t c}>0$. The latter inequality is guaranteed by $C 1$ and $C 2$. The necessary and sufficient conditions for $m_{2}^{t c}>0$ to hold are, respectively, $1+\gamma w>(1+w) \gamma^{0.5}$ (condition $C 4$ ) and $\hat{M}_{T}^{*} \geq \hat{m}_{2}($ condition $C 5)$.

Putting these results together we have that under $C 1-C 5$, the time consistent solution features: $\quad M_{T}^{* t c}, M_{T}, m_{2}^{t c}>0 ; M_{u}^{*}=0$ and $0<M_{1}<\hat{m}_{2}$. The ex ante optimal policy involves $M_{1}=m_{2}=\hat{m}_{2}$ and no permanent migration and no training. ${ }^{21}$

Summarizing: The inability to commit to temporary migration policy leads to smaller migration flows in the first stage. Further, in the second stage it leads to too much permanent migration and too little temporary migration.

Now consider how a bilateral agreement can improve upon this outcome by enabling

${ }^{21}$ It can be checked that conditions $C 1-C 5$ are all simultaneously satisfied under a range of parameter values. 
the host country to credibly commit to sending back a larger number of stage-1 immigrants. To this end, note that in the equilibria derived above, $m_{2}^{t c}>0$. This will play a useful role here. At the beginning of stage 1, the two countries sign a bilateral agreement specifying the following strategy: $M_{1}=M_{1}^{t c}+\varepsilon_{1}, M_{T}^{*}=M_{T}^{* t c}-\varepsilon_{T}$ where $\varepsilon_{1}, \varepsilon_{T}$ are some strictly positive numbers, $m_{2}=m_{2}^{t c}+\gamma \varepsilon_{T}$ and $M_{T}^{*}=M_{T}^{t c}-\varepsilon_{T} \geq 0$ and, if any country deviates from this then both the countries ban any further migration completely. ${ }^{22}$

In simple words, the proposed strategy implies a smaller number of permanent (trained) migrants and a larger flow of temporary migrants in both the stages relative to the outcome when policies are set unilaterally. Further, the cooperative effort requires that if any country deviates then there is no flow of new migrants thereafter. For this to be implementable and welfare enhancing we need to show that: (i) the proposed strategy is sub-game perfect (time consistent) in that no country has an incentive to deviate unilaterally at any stage, and (ii) welfare of each country is higher under this strategy than with policies set unilaterally. Part (ii) is simple and is discussed in detail in Appendix A. Part (i) can be shown as follows.

If a deviation occurs then both countries ban migration. This is time consistent since no country can do better by unilaterally deviating given the other country imposes the ban. This is the usual autarky-threat utilized in repeated games to sustain cooperation in a self-enforcing manner. Now consider the case when there is no deviation. To solve backwards assume that countries cooperate in stage 1 as required so that $M_{1}=M_{1}^{t c}+\varepsilon_{1}$. If the host country sets $M_{T}^{*}$ as required by the cooperative strategy then it will have no

\footnotetext{
22 One potential problem with implementing a ban on migration is the possibility of illegal migration. However, as mentioned above, the case being considered relates to skilled and semi-skilled workers. It is unlikely that a migration scheme for such workers can be operated clandestinely against the wishes of the source country.
} 
incentive to choose a value of $m_{2}$ other than the proposed one since this is ex-post optimal given $M_{T}^{*}=M_{T}^{* t c}-\varepsilon_{T}$. Hence consider its incentive to deviate from the value of $M_{T}^{*}$. The incentive to deviate will be maximum when all the $M_{1}$ migrants are trained in stage 1 and $H$ finds it optimal (with respect to $W_{2}$ ) to retain all of them . In this case a deviation implies that $H$ will have $\varepsilon_{1}+\varepsilon_{T}$ more trained migrants than under cooperation (note that $M_{1}^{t c}=M_{T}^{* t c}$ as shown above). The punishment involves loosing $m_{2}^{t c}+\gamma \varepsilon_{T}$ number of new migrants in stage 2. Thus, in the worst possible scenario for sustaining cooperation, the simple trade-off is $\varepsilon_{1}+\varepsilon_{T}$ trained migrants versus $m_{2}^{t c}+\gamma \varepsilon_{T}$ new migrants. Now allow $\varepsilon_{1}, \varepsilon_{T}$ to be arbitrarily small but strictly positive. It is evident that for these arbitrary small values the benefit from deviation will be arbitrarily small but the cost will be strictly positive since this involves loosing at least $m_{2}^{t c}$ number of new migrants which, as shown above, is strictly positive and independent of $\varepsilon_{1}$ and $\varepsilon_{T}$. Thus, even if all stage- 1 migrants were trained, the host country will not find it beneficial to deviate in the second stage for sufficiently small values of $\varepsilon_{1}, \varepsilon_{T}$. The source country has no incentive to deviate from the proposed strategy in stage 2 because it only stands to loose by moving to the no-migration outcome in stage 2. Now follow the same logic again to see that no country will want to deviate for sufficiently small values of $\varepsilon_{1}+\varepsilon_{T}$. We conclude from this that the proposed cooperative effort is sub-game perfect and no country will want to deviate from cooperating in each stage for sufficiently small values of $\varepsilon_{1}$ and $\varepsilon_{T}$.

Summarizing: Both countries prefer temporary migration only. Absent cooperation, the host country finds it too costly to achieve this outcome as it involves restricting all immigration in stage 1. The source also faces the same problem Cooperation makes it more costly 
for the host to retain migrants and permanent migration falls. This happens without either country having to reduce migration flows in stage 1. Cooperation is migration-liberalizing and promotes temporary over permanent migration.

We assumed above that, absent cooperation, the source country is inactive. One simple rationale for this is that the source country prefers permanent migration to no migration (assumed above). Consider the alternative scenario when the source prefers no migration to permanent migration. Under the conditions stated above we have already shown that all stage-1 migrants would be retained permanently by the host country. Given this expected behavior of the host country, the unilaterally optimal policy of the source country is to ban all migration in stage 1. Clearly, there are potential Pareto gains from cooperation: if the host can be forced to return stage- 1 immigrants (some or all) then the source will relax the ban on migration which will increase the welfare of both the countries. That such an agreement can be sustained in a self-enforcing way is also easy to establish, as discussed in more detail in the next sub-section. We can summarize our results here by noting that irrespective of the preference structure of the source country, there are Pareto gains from cooperation when the host country faces a commitment problem.

\subsubsection{Case B: When $C 3$ does not hold}

Maintain $C 1, C 2$ and suppose that $C 3$ does not hold. This case is different from Case A in that the ex ante optimal policy features some permanent migration of trained workers. This allows for the possibility that the commitment problem shown above may not arise here. We will focus on this case first since it is in sharp contrast to Case A. ${ }^{23}$ To this

\footnotetext{
${ }^{23}$ It is possible that even with $C 4$ violated the commitment problem may still remain. The structure of gains from cooperation is then similar to the one discussed above in Case A.
} 
end, we impose an additional restriction that $2(w+1)^{2}>\left(w+\gamma+S_{p}+c\right)^{2}$ (condition $C 7$ ). The structure of the equilibrium derived in section 2 applies here also. However, the key difference is in the equilibrium value of $M_{1}$. For Case A we argued that host has an incentive to reduce immigration in stage 1 to limit training and permanent migration in the second stage. This logic does not apply here since, with $C 3$ violated, some permanent migration of trained workers is ex ante optimal. It can be easily checked that with $C 3$ violated and $C 1, C 2, C 7$ holding, the ex ante optimal policy of the host implies $M_{1}>\hat{m}_{2}$. That is, ex ante, the gain from permanent trained immigrants is sufficiently large that the government invites more than $\hat{m}_{2}$ number of immigrants in stage 1 with the sole intention of training and retaining them for future benefit. The time consistent equilibrium solution is trivial now. The government simply implements $M_{1}$ exactly at the same level as implied by the ex ante optimal policy. Further from the solution for $m_{2}^{t c}$ outlined in section 2.2 it is clear that this will be equal to zero. It is straightforward to note from this that the full ex ante optimal policy is then time consistent too. Clearly, since the host implements its first best policy and the source is inactive there are not Pareto gains from cooperation. In fact, the host will be strictly worse off from any move to a different outcome.

However, gains from cooperation can still arise once we take into account the response of the source country which in turn depends on its preference structure. First consider the preference structure assumed above when the source country prefers temporary migration to permanent migration to no migration. As discussed in the previous paragraph, absent cooperation and an inactive source, the host country implements permanent migration only and the time consistent policy is ex ante optimal too. Allow the source country to be active 
now. Since it prefers permanent to no migration, its optimal policy (absent cooperation and given the strategy of the host country) is to do nothing. Of course, the source will be strictly better off with a shift from permanent to temporary migration but it cannot implement this unilaterally. It is also clear from this there are no potential Pareto gains from cooperation. Simply put, the host will be worse off from any shift towards temporary migration or change in overall migration levels from the non-cooperative time consistent solution. We summarize this finding below.

Summarizing: When the host prefers permanent migration to temporary migration and the source prefers temporary to permanent to no migration there is a conflict of interest between the two countries. Cooperative agreements can only strive to alter the distribution of welfare across countries but this will make the host country worse off.

Continuing, consider now the remaining case when the source prefers temporary to no migration to permanent migration. Since any positive level of emigration will be permanent, source bans all migration in the first stage as it prefers no migration to permanent migration. The resulting equilibrium will feature migration in stage 2 at level $\hat{m}_{2}$ and $M_{1}=0$. Pareto gains from cooperation are now evident. Both countries can be better off if they can implement a strictly positive level of temporary migration in the first stage. ${ }^{24}$ The only question that remains is whether such an agreement will be self-enforcing. To this end, consider the following strategy when the two countries cooperate. Let $M_{1}=\nu_{1}$, and $m_{2}=\hat{m}_{2}$ if all the $\nu_{1}$ migrants are returned after stage 1 and $m_{2}=0$ otherwise. Following the same logic as discussed above under Case A, it is simple to see that the strategy is

\footnotetext{
${ }^{24}$ It may or may not involve some permanent migration also.
} 
subgame perfect and all the $\nu_{1}$ migrants will be returned when $\nu_{1}$ is sufficiently small. Both the countries will be better off relative to the non-cooperative outcome: $S$ increases the flow of temporary migrants while $H$ gets some workers in stage $1 . \quad$ The resulting equilibrium will feature temporary migration only in stage 2 at level $\hat{m}_{2}$ and $M_{1}=0$. We consider the following coordination. Let $M_{1}=\nu_{1}$, and $m_{2}=\hat{m}_{2}$ if all the $\nu_{1}$ migrants are returned after stage 1 and $m_{2}=0$ otherwise. Following the same logic as discussed above under Case A, it is simple to see that the strategy is subgame perfect and all the $\nu_{1}$ migrants will be returned when $\nu_{1}$ is sufficiently small. Both the countries will be better off relative to the non-cooperative outcome: $S$ increases the flow of temporary migrants while $H$ gets some workers in stage 1. Of course, other Pareto improving and self enforcing agreements also exist. Now repeat the argument when the source country does not completely ban all emigration in stage 1 but limits to sufficiently so that $M_{1}=M_{T}<\hat{m}_{2} / \gamma$ and, consequently, $m_{2}>0$. A Pareto improving and self enforcing cooperative outcome can be easily sustained: set $M_{1}=\hat{m}_{2} / \gamma+\nu_{1}$ and $m_{2}$ the same as in the non-cooperative outcome if the host country returns $\nu_{1}$ number of migrants; if it fails to do so then set $m_{2}=0$.

Summarizing: When the source country prefers no migration to permanent migration and the host prefers permanent over temporary migration then the fear of brain-drain prompts the source country to ban migration. A cooperative agreement can reduce brain drain by enforcing return-migration. This is migration-liberalizing and generates Pareto gains globally.

An overview of the results in this section is presented in the following table: 


\begin{tabular}{c|c|c|c|}
\multicolumn{3}{c}{ Host } \\
\cline { 2 - 4 } Source & $\mathrm{T} \succ \mathrm{P} \succ \mathrm{N}$ & $\mathrm{P} \succ \mathrm{T} \succ \mathrm{N}$ \\
\cline { 2 - 4 } & $\mathrm{T} \succ \mathrm{P} \succ \mathrm{N}$ & Pareto gains & Distributional gains only \\
\cline { 2 - 4 } & $\mathrm{T} \succ \mathrm{N} \succ \mathrm{P}$ & Pareto gains & Pareto gains \\
\hline
\end{tabular}

T: Temporary migration, P: Permanent migration, N: No migration, $\succ$ : is strictly better than

\subsection{Multilateralism}

One objection to our results is that it deals with the potential benefits from labor agreements without explaining why efforts have not already been made to realize these benefits in the real world. We believe that a major problem is the existence of not one but multiple source countries which have failed coordinate their actions through a multilateral agreement. To see the nature of the problem, suppose that there are two identical source countries supplying labor to a single host country. Without much loss of generality, focus on the symmetric equilibrium when there is no cooperation between any two countries. The resulting equilibrium is simply the non-cooperative time consistent solution derived above with all migration levels (temporary and permanent) equally divided across the two source countries.

A multilateral regime is defined as one where a deviation by $H$ against any source country invites retaliation in the future from both the source countries. In contrast to this, in a bilateral regime $H$ can deviate against a single country without being punished by the other source country. We assume plausibly here that if there is continued cooperation between $H$ and any source country in stage 2 then it can hire as many new immigrants as it 
likes from this source country. ${ }^{25}$ The ineffectiveness of bilateral agreements is sustaining cooperation can now be easily established as follows.

In a multilateral regime if the host deviates from a proposed cooperative agreement then it will do so against both the source countries and will be punished by both of them. Thus, in this case we can simply bundle the two source countries into one and treat it as a single entity without affecting any of the results. However, this is exactly the same structure as already discussed above. We can conclude from this that there are gains from cooperation which can be realized in a multilateral world.

Now consider self-enforcing agreements in the bilateral regime. A candidate cooperative solution involves $H$ agreeing to retain $M_{T}^{1 c}\left(M_{T}^{2 c}\right)$ number of stage-1 immigrants from source country 1 (2) and returning the rest. If there is no deviation against country $1(2)$ then $H$ can hire as many workers as it wants from $1(2)$ in the second stage. ${ }^{26} \quad$ If $H$ deviates against 1(2) then, as above, it gets no new immigrants from 1(2) is stage 2. A necessary condition for $M_{T}^{1 c}, M_{T}^{2 c}$ to be self-enforcing is that:

$$
\begin{aligned}
& W_{2}\left(M_{T}^{1 c}+M_{T}^{2 c}, m_{2}^{1 c}+m_{2}^{2 c}\right) \geq W_{2}\left(M_{T}^{1 D}+M_{T}^{2 c}, m_{2}^{2 D}\right) \\
& W_{2}\left(M_{T}^{1 c}+M_{T}^{2 c}, m_{2}^{1 c}+m_{2}^{2 c}\right) \geq W_{2}\left(M_{T}^{1 c}+M_{T}^{2 D}, m_{1}^{2 D}\right)
\end{aligned}
$$

where $m_{2}^{i c}, i=1,2$ are the number of new immigrants that $H$ decides to hire from country $i$ if it cooperates with both the source countries; similarly $m_{2}^{i D}$ are the number of new immigrants

\footnotetext{
${ }^{25}$ If this assumption were imposed in the results derived above then it is simple to see that it will make no difference to any of our results.

${ }^{26}$ This is slightly different from the structure above where the cooperative agreement specified the number of new immigrants in stage 2. This was done for pure convenience and the assumption can be easily done away with without any change in our results. Allowing the host country to have as many immigrants as it wants in stage 2 if it cooperates is also more realistic due to unanticipated shocks.
} 
that $H$ gets if it cooperates with $i$ but deviates against the other source country; lastly, $M_{T}^{i D}$ is the number of trained immigrants belonging to country $i$ that $H$ decides to retain if it deviates against the same source country.

Consider the first inequality. The left hand side of this is the benefit to $H$ from cooperating with both the source countries while the right hand side is the benefit to it from deviating against country 1 alone. For the proposed cooperation to be self-enforcing the former must be at least as much as the latter, otherwise $H$ will deviate against country 1 . The second inequality is similar and captures the incentive structure of $H$ to cooperate relative to deviate against country 2. Can these inequalities be satisfied at any level of $M_{T}^{1 c}, M_{T}^{2 c}$ below $M_{T}^{n}$ ? To answer this question we note that current migration levels are quite small relative to the available supply of potential immigrants in the world. That is, if $H$ deviates against say country 1 alone then it can meet its entire demand for new immigrants in the next stage from country 2 alone. Hence, set $m_{2}^{2 D}=m_{2}^{1 c}+m_{2}^{2 c}$. That is, number of new immigrants that $H$ can get by cooperating with both the countries can be simply obtained by cooperating with just country 2 . Thus, the threat of future retaliation by country 1 is ineffective in the bilateral world. The immediate outcome of this is that $H$ will always find it optimal, ex post, to deviate against country 1 . This implies that the only agreement that can be sustained between $H$ and country 1 is the simple non-cooperative solution from which $H$ will have no incentive to deviate. Suppose that this holds in the remainder of our discussion. Now consider if any cooperation can be sustained between $H$ and country 2 . Note that our discussion above for country 1 was independent of the value of $M_{T}^{1 c}$. Hence we can simply repeat the argument above for country 2 also. Hence, $H$ will always find it in 
optimal to deviate against country 2 from any proposed cooperative solution. Putting these results together we get a simple result that in the bilateral regime, the unique self-enforcing outcome is simply the time consistent solution derived above. ${ }^{27} \quad$ Thus, coordination among source countries is necessary (and sufficient) to translate the potential gains from cooperation into reality. ${ }^{28}$ To conclude the section we summarize this result as follows.

Summarizing: In a bilateral regime the source country will always have an incentive to deviate from any possible cooperative agreement with any source country. Consequently, in each bilateral pair the cooperative effort will degenerate to the non-cooperative solution. The unique self-enforcing outcome is the same as the non-cooperative time consistent solution. ${ }^{29}$

27 It is important to note here that we are restricting ourselves to only those agreements that are selfenforcing. This is common in the general literature on cooperation in repeated games. The rationale being that some cooperation is better than no cooperation (deviation and subsequent punishment). In the context of our model one possible caveat can arise in the following way. Suppose that in the bilateral regime $H$ agrees to the most cooperative solution that be implemented in the multilateral regime. Clearly, ex post, $H$ will deviate against say country 1 as established above. However, having done so it will not find it optimal to deviate against country 2 now. Thus, we may argue that by allowing this strategy can sustain cooperation between $H$ and country 2. Our motivation in ruling out such strategies or dummy agreements is as follows. Firstly, a multilateral institution will be required to make transparent to country 2 the agreement between $H$ and country 1. This is not possible in a strictly bilateral world. Secondly, international negotiations are costly (transaction costs) and the source country, realizing that $H$ will deviate for sure, does not gain anything. Hence, it will simply refuse to part of such a strategy to begin with. Thirdly, each source country would prefer the other source country to be part of the dummy agreement. A simple waiting game will arise where no source country will have an incentive to relent. Fourthly, in the real world we observe a large number of source countries supplying labor to a single host country like the US. Simple extension of the results above suggest that the host country will have to sign dummy agreements with all the source countries except one. This has its obvious problems in terms of information flows and other problems noted here and is highly unlikely.

${ }^{28}$ The same argument holds for more than two source countries. All that is required is that there be at least two countries from which the host can potentially meet most of its demand for labor.

${ }^{29}$ This issue is not new and has been widely discussed in the literature on multilateralism versus bilateralism. See, for example, Maggi (1999), p. 208. However, as we have argued, it is particularly important in the context of migration as it renders bilateral approach highly ineffective. 


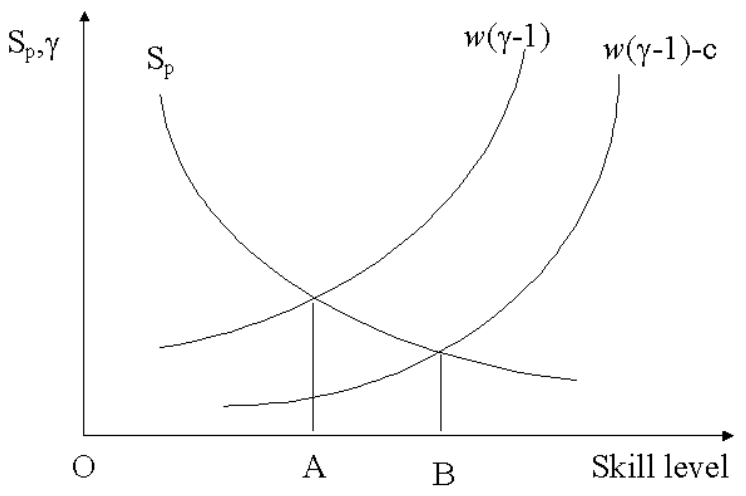

Figure 1: Summary graph

\section{Section 4: Implications of the results and testable hypotheses}

The following discussion brings out the implications of our analysis for the interplay between social preferences, dynamics of learning and the skill level of immigrants.

The key elements driving our results are captured by the parameters $S_{p}, \gamma$ and $c$. Figure 1 shows how these can be plausibly seen to relate to the skill level of immigrants.

Consider the value of $S_{p}$ first. Anecdotal evidence suggests that the social cost to the host is decreasing in the skill level of immigrants. One reason for this is that more skilled immigrants are better able to assimilate into the local culture than less skilled ones, and impose a smaller net fiscal burden. This is captured in the downward sloping graph of $S_{p}$. Similarly, training and skill enhancement are less important for workers with low skill levels than for those at the high skill end. Hence, we can expect that the surplus from training, ex ante and ex post, is increasing in the skill level as shown in the graph by $w(\gamma-1)-c$ and $w(\gamma-1)$, respectively. The region $\mathrm{AB}$ then captures the interval of skill levels over which 
temporary migration is optimal ex ante but not time consistent (conditions $C 1$ and $C 3$ hold). The region to the right of $\mathrm{B}$ features permanent migration as the equilibrium outcome when policies are set unilaterally. This is optimal for the host country, ex ante and ex post. Lastly, when immigrants have low skill levels (region to the left of A), there is temporary migration only even without cooperation (section 3.2). This is consistent with existing evidence in that in most host countries legal permanent migration is largely restricted to immigrants with high skill levels. ${ }^{30}$

While a formal empirical investigation of our predictions is beyond the scope of this paper, we suggest testable hypothesis for future work. Given that there is little enforcement of cooperative solutions, our results imply that we should be observing migration patterns implied by the (non-cooperative) time consistent solution. One straightforward implication of this is that for countries in the interval $\mathrm{AB}$ in the previous graph, temporary migration is used as a conduit for permanent migration and that this is due to the dynamic structure of learning and a strictly positive social cost $\left(S_{p}>0\right)$. There is some evidence suggesting that a substantial number of temporary visa holders are granted permanent residency. For example, Lowell (2000) argues that over $40 \%$ of H-1Bs in early 1990s were converted to permanent residency in the U.S. and that this is likely to climb to about $50 \%$ by 2007 . However, it is difficult to say that this adjustment to permanent status is driven only by the dynamics of learning. Other factors may be at play. For example, host countries may use temporary migration as a screening devise to separate high ability from low ability agents before deciding to grant permanent residency. We leave this as an important issue for future

\footnotetext{
${ }^{30}$ Much of permanent residency granted to unskilled immigrants is based on "family reunification" grounds which is not the focus of this paper. We restrict ourselves here to "economic migration" only.
} 
research.

Other testable results of the model are the following. Firstly, the model predicts countries which have higher aversion (social cost) to immigration will have a preference for temporary over permanent migration over a higher range of skills. We find some support to this from the survey data published by European Monitoring Centre on Racism and Xenophobia, 2001. That is, EU countries where a majority of citizens agreed more with the idea that immigrants enrich the cultural life of their country also showed a greater aversion to sending non-EU legal immigrants back to their home country if they were unemployed ("conditional repatriation"). The coefficient of correlation was found to be 0.66 and it jumps up to 0.74 if the outlier Denmark is dropped. For more details, see Table B1 in Appendix B.

Secondly, the results suggest that host countries will typically prefer to retain immigrants in sectors where there are large returns to investment in training. Again there is some casual evidence that from the US H1-B scheme, employees in software development are more likely to receive extensions of stay than some other categories where learning is less important.

Lastly, there is significant variation in the composition of migration (temporary versus permanent) across time. For example, in the Lowell (2000) study discussed above, the adjustment of H-1Bs to permanent status was about 5\% in 1972 and has gradually risen to over $40 \%$ currently. Our model suggests that changes in $S_{p}, \gamma$ over time could be important in this context but further work is required to confirm (or reject) this. 


\section{Conclusion}

The issue of temporary versus permanent migration is today central to the design of migration policies. We showed that unilateral migration policies are globally inefficient mainly because they lead to too much permanent migration and too little temporary migration. A key reason is identified to be the time inconsistency of migration policy: in a number of cases, temporary migration is ex ante optimal but not ex post desirable. We focused on investments in training by firms, but the time inconsistency problem could arise due to any private choices that alter the ex post welfare calculus - e.g. when nationals invest in relationships with and marry temporary immigrants.

Existing international agreements, such as the General Agreement on Trade in Services, have failed to improve on unilateral outcomes because they primarily seek to induce host countries to make commitments to allow entry. Instead, Pareto gains could be realized through multilateral agreements that enable host countries to commit to repatriation. Ironically, greater openness could come by creating a mechanism to commit to return than through one that enables commitments to entry.

To make our argument, we made a number of simplifying assumptions. The distinction between temporary and permanent migration was based only on the associated social cost and the dynamics of learning by migrants. But there are other important differences between the two types of migration. For example, from the host country's point of view, temporary presence entails other "turnover" costs such as limiting social integration. From the source country's point of view, temporary migration may avert the costs of brain drain, but it deprives migrants of opportunities for cumulative learning and saving - which could 
have significant long-term benefits for source countries. Our analysis can be extended to incorporate these dimensions.

There could also be other important elements of international cooperation on labor mobility. The framework of existing trade agreements implies that obligations are assumed by host countries alone, to provide market access on a non-discriminatory basis regardless of conditions in source countries. In contrast, the assumption of obligations by source countries also is a key element of regional trade agreements (e.g. NAFTA and APEC) that have facilitated mobility of the skilled, and of bilateral labor agreements (e.g. between Spain and Ecuador) that have to a limited extent improved temporary access for the unskilled. Source country obligations include pre-movement screening and selection, accepting and facilitating return, and commitments to combat illegal migration. How these elements can be incorporated in a more general agreement on migration is the subject of a companion paper. 


\section{Appendix A}

Welfare improvement from cooperation in Case A: The source country is better off under cooperation since there is a larger flow of temporary migrants in stage 1 and in stage 2 it gets to replace $\varepsilon_{T}$ number of otherwise permanent migrants with $\gamma \varepsilon_{T}$ temporary ones. On both these counts its welfare will increase. Now consider the host country. The main point here is that the higher value of $M_{1}$ under cooperation does not by itself increase its welfare since it could do so even unilaterally. The key point here is that private firms correctly anticipate

that, ex post, the government will not retain more than $M_{T}^{* t c}-\varepsilon_{T}=\hat{M}_{T}^{*}-\varepsilon_{T}$ number of trained migrants as this will trigger a much larger punishment when $\varepsilon_{T}, \varepsilon_{1}$ are sufficiently small. Thus, downward revision in the expectation of firms about the future of stock of trained migrants that will be retained implies that each firm will now train a smaller number of migrants. As this occurs, the host country's ex ante welfare will rise (under $C 3$ ). Also, there is some further gain in for the host country since with $M_{1}^{t c}<\hat{m}_{2}$ as shown above, $W_{1}$ is strictly increasing in $M_{1}$ with $M_{T}$ held constant.

Summarizing, we have shown that a self-sustaining cooperative effort between the two countries can improve the welfare of the both the countries relative to the time consistent solution obtained when policies are set unilaterally. We showed that this holds for sufficiently small levels of cooperation (small values of $\varepsilon_{1}, \varepsilon_{T}$ ). The exact magnitude of cooperation that is possible will depend on the structure of the model and parameter values. 


\section{Appendix B: Evidence of social cost in EU}

Table B1: Acceptance of citizens of other countries of the European Union, who wish to settle in the respondent's country: For year $2000, \%$ of respondents reporting:

\begin{tabular}{|c|c|c|c|}
\hline Country & Accepted without restriction & Accepted with restriction & Not accepted \\
\hline Denmark & 60 & 36 & 1 \\
\hline Sweden & 58 & 35 & 2 \\
\hline Spain & 56 & 36 & 1 \\
\hline Italy & 54 & 38 & 3 \\
\hline Finland & 48 & 44 & 5 \\
\hline Portugal & 41 & 44 & 6 \\
\hline Greece & 39 & 52 & 6 \\
\hline Luxembourg & 38 & 53 & 6 \\
\hline France & 38 & 51 & 6 \\
\hline Belgium & 38 & 45 & 13 \\
\hline Ireland & 34 & 51 & 5 \\
\hline Netherlands & 26 & 59 & 11 \\
\hline Germany & 26 & 53 & 14 \\
\hline UK & 25 & 50 & 14 \\
\hline Austria & 24 & 52 & 6 \\
\hline EU 15 & 39 & 46 & 8 \\
\hline
\end{tabular}

The remaining respondents reported "do not know".

Source: European Monitoring Centre on Racism and Xenophobia, 2001. 
Table B2: The presence of people from these minority groups is a cause of insecurity For year $2000, \%$ of respondents reporting:

\begin{tabular}{|l|c|c|}
\hline Country & Agree & Disagree \\
\hline Greece & 77 & 19 \\
\hline Denmark & 60 & 33 \\
\hline Belgium & 56 & 35 \\
\hline France & 51 & 41 \\
\hline Germany & 46 & 34 \\
\hline Portugal & 45 & 41 \\
\hline Netherlands & 45 & 44 \\
\hline Austria & 44 & 39 \\
\hline Ireland & 42 & 43 \\
\hline Luxembourg & 40 & 47 \\
\hline Italy & 38 & 46 \\
\hline Spain & 34 & 56 \\
\hline UK & 32 & 48 \\
\hline Finland & 32 & 61 \\
\hline Sweden & 24 & 66 \\
\hline EU 15 & 42 & 43 \\
\hline
\end{tabular}

The remaining respondents reported "do not know".

Source: European Monitoring Centre on Racism and Xenophobia, 2001. 
Table B3: Sum index 'restrictive acceptance of immigrants', by country for 2000

\begin{tabular}{|l|c|c|}
\hline Country & mean & standard deviation \\
\hline Germany & 0.52 & 0.22 \\
\hline Belgium & 0.51 & 0.26 \\
\hline UK & 0.51 & 0.25 \\
\hline Greece & 0.49 & 0.21 \\
\hline Luxembourg & 0.48 & 0.22 \\
\hline France & 0.44 & 0.25 \\
\hline Ireland & 0.43 & 0.22 \\
\hline Portugal & 0.43 & 0.26 \\
\hline Austria & 0.43 & 0.20 \\
\hline Finland & 0.39 & 0.22 \\
\hline Italy & 0.35 & 0.25 \\
\hline Denmark & 0.31 & 0.22 \\
\hline Spain & 0.29 & 0.25 \\
\hline Sweden & 0.28 & \\
\hline EU & 0.43 & 0.22 \\
\hline
\end{tabular}

0 ... maximum acceptance, $1 \ldots$ minimum acceptance. A higher index score indicates more restricted acceptance of immigrants (working immigrants, refugees, EU citizens, etc.). Source: European Monitoring Centre on Racism and Xenophobia, 2001. 
Table B4: Settler arrivals by major occupation categories in Australia

\begin{tabular}{|l|c|}
\hline & \% of total \\
\hline Managers/Adm. & 5.4 \\
\hline Professionals & 21.7 \\
\hline Associate Professionals & 5.1 \\
\hline Tradepersons and related workers & 6.2 \\
\hline Advanced Clerical and Service workers & 1.2 \\
\hline Intermediate Clerical, Sales and Service workers & 4.6 \\
\hline Intermediate Production and Transport workers & 0.96 \\
\hline Elementary Clerical, Sales and Service workers & 1.6 \\
\hline Laborers and related workers & 0.76 \\
\hline Not in workforce & 43.1 \\
\hline Not in employment & 3.7 \\
\hline Not stated & 5.6 \\
\hline Total (absolute value) & 914 \\
\hline
\end{tabular}

Source: Department of Immigration and Multicultural and Indigenous Affairs, Australia. ${ }^{31}$

31 The percentage figures may not add up to 100 due to rounding of decimals. 


\section{Appendix C: Extensions}

The results established above were derived under some restrictive conditions and behavioral assumptions. Most of these were utilized to simplify the presentation of the findings. We discuss below how some of these can be easily relaxed without altering our main results. C1: Active source country in Case A

In the previous section we showed that Pareto-improving agreements can be sustained in a self-enforcing way through simple coordination between the two countries. For case A the analysis was based on the assumption that the initial time consistent equilibrium features the source country being completely inactive in its emigration policy. This assumption can be easily done away with while still preserving the basic results as follows. In stage 2 the source country will have no incentive to limit the flow of new emigrants as these are all temporary migrants. This implies that equilibrium value of $m_{2}^{t c}$ will be given by the same function as derived in the previous section. This implies that $m_{2}^{t c}$ will still be strictly positive provided that $M_{T}^{t c}$ value is unchanged or lower than the one when the source country government was inactive. Next it is trivial to note that any intervention by the source country can only lower the value of $M_{1}$ and hence $M_{T}^{t c}$ since it cannot force the host country to increase

its immigration. Thus, the resulting time consistent equilibrium will feature $m_{2}^{t c}>0$ and $M_{T}^{t c}=M_{1}^{t c} \geq 0$. If the previous inequality holds strictly then this is qualitatively the same situation as discussed in section 2 and, if $M_{1}^{t c}=0$ then the threat of banning future migration can sustain cooperation on the part of both the countries in exactly the same way as discussed in the previous section.

C2: Asymmetric quota rule 
In section 2 we assumed that the quota rule is symmetric across firms. Our results are virtually unchanged if an asymmetric rule were used instead. Consider for example an asymmetric distribution of $M_{1}$ across firms. Since capital is fully mobile, firms with a smaller number of migrants in stage 1 will experience lower marginal productivity of capital than others. The freely functioning capital market will reallocate capital until these marginal productivity are equalized. Given identical CRS technology across firms, this will happen if and only if the capital to labor ratio is equalized across firms. As long as firms continue to be price-wage-takes, their behavior is completely determined by the capital-labor ratio and not their absolute size. Thus, this situation is exactly the same as the symmetric one in section 2 .

Next consider asymmetries in the distribution of permanent (trained) migrants across firms. For a meaningful comparison, hold the overall aggregate value of $M_{T}^{*}$ fixed. Suppose there are 2 firms with each assigned 2 units of trained migrants in the symmetric case. Now suppose one firm believes that it will get to retain 3 migrants and other firm believes that it will get to retain only 1 migrant. The question is will the favored firm train 3 migrants and the other only 1? The answer to this is simple. The average cost of training is independent of the number of trainees. The marginal benefit as perceived by the firms is also independent of the scale of operation since each firm takes the price as given and perceives the marginal productivity of labor in the future stage to be same across firms due to capital mobility. With the incentive to train migrants independent of the scale of operation of any single firm, the stated asymmetry will have no effect on the number of migrants trained in the aggregate. Lastly, consider asymmetry in the distribution of new stage-2 migrants across different 
firms. The decision to train migrants will not be affected by this for any firm. The logic is same as in the previous paragraph. The average (and marginal) cost of training is independent of stock of new migrants with any firm. The marginal benefit from training depends upon the expected future price and expected marginal productivity of the trained migrant. The former is independent of the firm-characteristics (since firms are atomistic) while the latter will is fixed at the existing rental value of capital ${ }^{32}$ which each firm treats as independent of its own structure.

\section{C3: Naive expectations}

An alternative to the structure of expectations in the previous section is for firms to hold naive expectations. For example, we can specify a model where each firm holds some arbitrary beliefs about the endogenous variables and then search for the ones which will be realized ex post. In the context of this paper the main problem with this approaches that gives rise to self-fulfilling multiple equilibria. For example, if each firm believes that no migrants will be retained in the future then it will not train any migrants and the expectation will be realized, ex post. However, if they believe that an arbitrarily small number of trained migrants will be retained then they will train some of their migrants and, ex post, the government will retain them. Our main results are in fact consistent with such multiple equilibria in the following way. With multiple time consistent equilibria the host country can be stuck at a sub-optimal one relative to the case when full commitment is feasible. This is precisely what we will show in our results under the assumed structure of expectations.

\footnotetext{
32 That is, if the firm perceives that the marginal productivity of trained migrant is higher due to a smaller number of new migrants assigned to it then it will also perceive that the marginal productivity of its capital is lower. Hence, with the rental on capital unchanged, the firm will lend out some of its capital until this difference is completely eliminated.
} 
Secondly, with multiple equilibria, bilateral agreements can be used to shift the equilibrium towards more desirable ones. This is exactly what we intend to show. Thus, we believe that there is not much loss of generality to our results in the structure of expectations that we have utilized in this model. 


\section{References}

Angrist, Joshua D. and Adriana D. Kugler (2002), "Protective or Counter-Productive? Labor Market Institutions and the Effect of Immigration on EU Natives," IZA Discussion Paper No. 433.

Auerbach, Alan and P. Oreopolis (2000), "The Fiscal Impact of U.S. Immigration: A Generational Accounting Perspective," in James Poterba edited, Tax Policy and the Economy, Volume 14, MIT Press, Cambridge, MA.

Becker, G. (1971), The Economics of Discrimination, The University of Chicago Press, Chicago.

Bhagwati, J. (1991), "Free Traders and Free Immigrationists: Strangers or Friends?," Russell Sage Foundation, Working Paper 20.

Bliss, Christopher (1994), "Trade Blocks and Migration," in his Economic Theory and Policy for Trading Blocks, Chapter 5, Manchester University Press.

Borjas, George J. (1995), "The Economic Benefits from Immigration," Journal of Economic Perspectives, 9(2), 3-22.

Borjas, George J. (1999), Heaven's Door: Immigration Policy and the American Economy, Princeton University Press, Princeton, NJ.

Borjas, George J. (2003), "The Labor Demand Curve Is Downward Sloping: Reexamining the Impact of Immigration On the Labor Market," Quarterly Journal of Economics, 118, 4(1), 1335-1374.

Carlton, Dennis W. (1995), "Economic Organization and Conflict," Journal of Institutional and Theoretical Economics, 151(1), pp. 218-236. 
Campbell, Eugene, K. (2003), "Attitudes of Botswana Citizens toward Immigrants: Signs of Xenophobia?," International Migration, 41(4).

CLBC (2002), "Employment Sponsored Training among Recent Immigrants," Canadian Labour and Business Centre.

Cohen, Sarit and Zvi Eckstein (2002), "Labor Mobility of Immigrants: Training, Experience, Language and Opportunities," IZA Discussion Paper No. 519.

Coleman, James S (1987), "Norms as Social Capital," in G. Radnitzky and P. Bernholz edited Economic Imperialism: The Economic Method Applied Outside the Field of Economics, Paragon.

(1988), "Social Capital in the Creation of Human Capital," American Journal of Sociology, 94(1): pp. S95-S120.

(1990), Foundations of Social Theory, Harvard University Press.

Docquier, F. and A. Marfouk (2004), "Measuring the International Mobility of Skilled Workers (1990-2000)," Policy Research Working Paper 3381, Release 1.0, The World Bank, Washington DC.

Dustman, C. (1998), "Temporary Migration, Human Capital, and Language Fluency of Migrants," Mimeo, University College, London.

Dumont, Jean-Christophe and Georges Lemaitre (2004), "Counting Immigrants and Expatriates In OECD Countries: A New Perspective," Working Paper, OECD.

Dustmann, C. and I. Preston (2000), "Racial and Economic Factors in Attitudes to Immigration," Mimeo, available at www.homepages.ucl.ac.uk/ uctp100/immig.htm.

Dustmann, C. and Oliver Kirchkamp (2002), "The Optimal Migration Duration and Activity 
Choice After Re-migration," Journal of Development Economics, 67, 351-372.

Ellerman, David (2003), "Policy Research on Migration and Development," World Bank Policy Research Working Paper Series, No. 3117, World Bank, Washington DC.

Fetzer, Joel S. (2000), "Economic Self-Interest or Cultural Marginality? Anti-immigration

Sentiment and Natavist Political Movements in France, Germany and the USA," Journal of Ethnic and Migration Studies, 26(1).

Hatton, Tim and Massimiliano Tani (2003), "Immigration and Inter-Regional Mobility in the U.K., 1982-2000," CEPR Discussion Paper 4061.

Hill, J.K (1987), "Immigrant Decisions Concerning Duration of Stay and Migration Frequency," Journal of Development of Economics, 25, 221-234.

Knack, S. and P. Keefer (1997), "Does Social Capital Have an Economic Payoff? A CrossCountry Investigation," Quarterly Journal of Economics, CXII, pp. 1251-88.

Lahav, Gallaya (2004), Immigration and Politics in the New Europe, Cambridge University Press.

Lee, Ronald and Timothy Miller (2000), "New Issues in Immigration," American Economic Review, 90(2), 350-354.

Lowell, Lindsay (2000), "H-1B Temporary Workers: Estimating the Population," Working Paper 12, Georgetown University.

Maggi, Giovanni (1999), "The Role of Multilateral Institutions in International Trade Cooperation," American Economic Review, 89(1), pp. 190-214.

Mayda, Anna Maria (2004), "Who is Against Immigration? A Cross Country Investigation of Individual Attitudes Towards Immigrants," IZA DP No. 1115. 
O'Rourke, Kevin H. and Richard Sinnot (2004), "The Determinants of Individual Attitudes Towards Immigration," Working Paper, Dublin Economics Department, Trinity College.

Putnam, R.D. (1995), “Bowling Alone: America's Declining Social Capital," Journal of Democracy, 6(1), pp. 65-78.

Rapoport, Hillel and A. Weiss (2000), "The Optimal Size of a Minority," Mimeo, Department of Economics, Bar-Ilan University, Ramat Gan, Israel.

Rivera-Batiz, Francisco L. (2001), "International Migration, Remittances and Economic Welfare in the Source Country," Journal of Economic Studies, 13(3), pp. 3-19.

Schiff, M. (1992), "Social Capital, Labor Mobility, and Welfare: The Impact of Uniting States," Rationality and Society, 4(2), pp. 157-175.

(?), "Labor Market Integration in the Presence of Social Capital," Working Paper, Development Research Group, The World Bank.

- _- - _ (2000), "Love Thy Neighbor: Trade, Migration, and Social Capital," Working Paper, Development Research Group, The World Bank.

Stark, O., C. Helmenstein and Y. Yegorov (1997), "Migrants Savings, Purchasing Power Parity, and the Optimal Duration of Migration," International Tax and Public Finance, 4, 307-324.

Stark, Oded and Yong Wang (2002), "Inducing Human Capital Formation: Migration As a Substitute for Subsidies," Journal of Public Economics, 86, pp. 29-46.

Storesletten, Kjetil (2000), "Sustaining Fiscal Policy Through Immigration," Journal of Political Economy, 108(2), 300-323.

Winter-Ebmer and Zweimüller (1998), "Immigration, Trade and Austrian Unemployment," 
in Landesmann M and E. Streissler edited Unemployment in Europe, MacMillan, London. Winters, L. Alan, Terrie L. Walmsley, Zhen Kun Wang and Roman Grynberg (2002), "Negotiating the Liberalization of the Temporary Movement of Natural Persons," Discussion Paper 8\%, University of Sussex, Brighton.

Winters, L. Alan, S. Commander and Mari Kangasniemi (2003), "The Brain Drain: Curse or Boon?," IZA, DP No. 809, Institute for the Study of Labor. 